\title{
FACTORS ASSOCIATED WITH BUSINESS PROCESS IN HOSPITAL: A SYSTEMATIC REVIEW
}

\author{
Arinahaq, Anhari Achadi \\ Masters Program in Public Health, Faculty of Public Health, Universitas Indonesia
}

\begin{abstract}
Background: In order to improve the efficiency and effectiveness of company performance, hospitals must be competitive in maintaining service processes. It requires efficient business process. Business process management or business process reengineering must adapt to hospital market segment and avoid complex and fragmented health services. The study aimed to systematically review the factors associated with business process in hospital.

Subjects and Method: This was a systematic review about the management of business processes in the hospital. This study searched articles from two scientific literature databases, namely ProQuest and Scopus. The keywords were "business process", "business process re-engineering hospital", and "business process management". The inclusion criteria were English, scientific journals, papers in conference and proceedings, from 2009-2019, and all international journals. The articles were collected based on PRISMA.

Results: Seven articles met the inclusion criteria. Five articles reported that the involvement of hospital management and the use of business process method influenced the success of business process. Three articles reported that information technology support was closely related to implementation of business process. An article reported the need for a business process team, for the implementation of hospital business process.

Conclusion: Hospital business process is related to management involvement in designing business process. The determination of hospital information system and team cohesiveness are needed in the design and implementation of hospital business process.
\end{abstract}

Keywords: business process management, business process reengineering, hospital

\section{Correspondence:}

Arinahaq. Masters Program in Public Health, Faculty of Public Health, Universitas Indonesia. Email: arinahaq@ui.ac.id. Mobile: 08111456287. 